\section{IN THE NEWS}

Inherited headache

Taking painkillers while pregnant might be bad news for women's grown-up sons if a recent study in rats is anything to go by.

Stuart Amateau and Margaret McCarthy from the University of Maryland dosed the drinking water of pregnant rats with aspirin for a 2-week period, during which they gave birth. At maturity, their male offspring were much less interested than untreated controls in copulating with receptive females. This reticence correlated with a reduced number of neural connections in the preoptic area, a brain region implicated in sexua behaviour.

Aspirin blocks the production of prostaglandins, which are integral to pain pathways. Amateau and McCarthy were surprised by their findings because "There was no indication that [prostaglandins] were involved in brain development or sex-specific effects" (New Scientist, 23 May).

Should pregnant women be concerned? Non-steroida anti-inflammatories such as aspirin are used to prevent miscarriage and to treat premature babies with heart defects. According to scientists at Michigan University, "Even now there may be some husband out there saying ... 'Sorry, dear, not tonight. My mother had a headache 30 years ago'" (BBC News online, 24 May).

But leuan Hughes at Cambridge University insists that more data are needed before any changes to medical practice are made. "It would be a quantum leap to extrapolate this [rat] data to humans," he told the Guardian (24 May)

Nevertheless, Marc Breedlove from Michigan State told Nature Neuroscience - in which the new study is published that "It is a reminder for pregnant women to use caution" when selfmedicating.

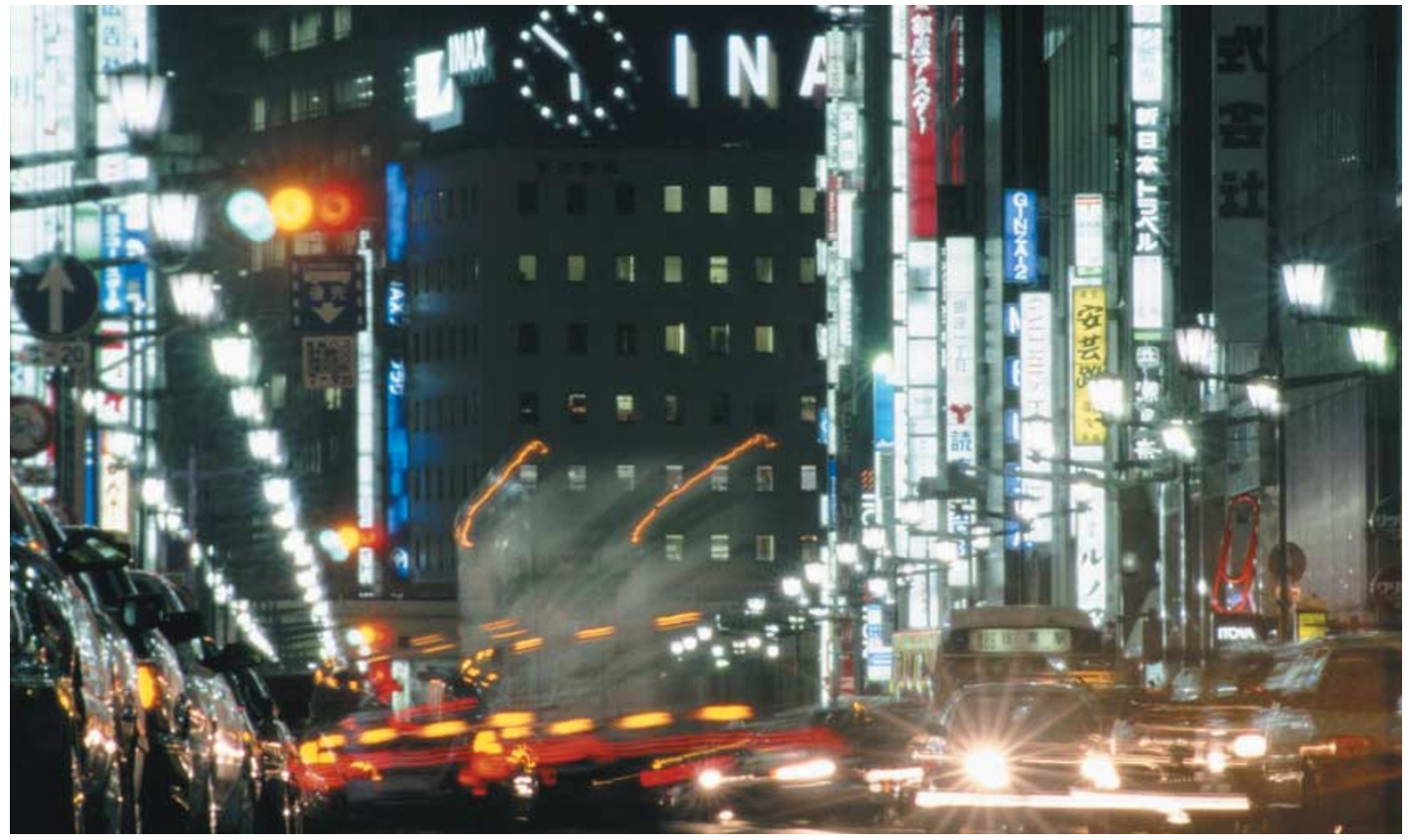

DEVELOPMENT

\title{
Transient traffic control
}

The cessation of transient fluctuations in the concentration of intracellular calcium halts the migration of granule cells in the developing cerebellum, according to an article in the Proceedings of the National Academy of Sciences, USA.

After their birth in the external granular layer, granule cells in the developing cerebellum must traverse the expanding molecular layer and the adjacent Purkinje cell layer to reach their final destination in the internal granular layer (IGL). To test the hypothesis that calcium signals regulate this process, Tatsuro Kumada and Hitoshi Komuro measured and manipulated the frequency of calcium transients in migrating granule cells.

As cell-cell contact and external signals are thought to influence granule cell migration, the duo used an acute cerebellar slice preparation to preserve structural integrity and the cellular milieu. In slices from 10-dayold mice, they detected distinct fluctuation patterns of calcium transients in the somata of moving cells. As cells neared a boundary between layers, the frequency of transients decreased. This decrease was always associated with a slowing of cell movement. About 17 minutes before migrating granule cells became permanently anchored in the IGL, calcium transients in the cells ceased completely.

Pharmacological manipulation of transients reinforced this correlation between the frequency of fluctuations in calcium concentration and the rate of cell motion. Inhibiting calcium transients - by chelating intracellular calcium, lowering the extracellular concentration, preventing release from internal stores, or blocking influx through voltage-gated or glutamate receptor-coupled channels - slowed or prematurely halted granule cell migration in the IGL.

Conversely, increasing the frequency of transients by stimulating the release of calcium from internal stores accelerated the movement of cells and delayed the cessation of migration. Some cells even began to travel backwards. Interestingly, this effect was only observed at the bottom of the IGL, the ultimate destination of granule cells under normal conditions. At the top of the IGL, near its border with the Purkinje cell layer, increasing the intracellular calcium concentration did not increase the frequency of calcium transients. Nor did this manipulation alter the rate of granule cell movement.

So Kumada and Komuro have shown that the frequency of calcium transients controls the rate of granule cell migration in the early postnatal cerebellum. But what of the role of external cues? By tracking the migration of isolated granule cells in culture, the pair showed that intrinsic programmes determine the timing of the loss of calcium transients and thereby the cessation of migration. In the absence of external modulators or cell-cell contact, calcium transients ceased after 50-60 hours and cells became stationary. Intriguingly, this period is approximately equivalent to the duration of granule cell migration in vivo.

Suzanne Farley

\section{(2) References and links}

ORIGINAL RESEARCH PAPER Kumada, T. \& Komuro, $\mathrm{H}$. Completion of neuronal migration regulated by loss of $\mathrm{Ca}^{2+}$ transients. Proc. Natl Acad. Sci. USA 101, 8479-8484 (2004)

FURTHER READING Komuro, $\mathrm{H}$ \& Yacubova, E Recent advances in cerebellar granule cell migration. Cell. Mol. Life Sci. 60, 1084-1098 (2003) 